\title{
Substrate Stiffness and Oxygen Availability as Regulators of Mesenchymal Stem Cell Differentiation within a Mechanically Loaded Bone Chamber
}

\author{
Darren Paul Burke ${ }^{1,2}$, Hanifeh Khayyeri ${ }^{3}$, Daniel John Kelly ${ }^{1,2,4}$
}

\begin{abstract}
${ }^{1}$ Trinity Centre for Bioengineering, Trinity Biomedical Sciences Institute, Trinity College Dublin, Dublin, Ireland.

${ }^{2}$ Department of Mechanical and Manufacturing Engineering, School of Engineering, Trinity College Dublin, Dublin, Ireland.

${ }^{3}$ Division of Solid Mechanics, Department of Orthopaedics, Lund University, Lund, Sweden

${ }^{4}$ Advanced Materials and Bioengineering Research Centre (AMBER), Trinity College Dublin, Dublin, Ireland.
\end{abstract}

Daniel J Kelly, PhD (*Corresponding author)

Trinity Centre for Bioengineering, Trinity Biomedical Sciences Institute, Trinity College Dublin, Dublin, Ireland.

Telephone: +353-1-8963947

Fax: $+353-1-6795554$

Email: kellyd9@tcd.ie 


\begin{abstract}
Mechanical stimuli such as tissue deformation and fluid flow are often implicated as regulators of mesenchymal stem cell (MSC) differentiation during regenerative events in vivo. However, in vitro studies have identified several other physical and biochemical environmental cues, such as substrate stiffness and oxygen availability, as key regulators of stem cell fate. Hypotheses for how MSC differentiation is regulated in vivo can be either corroborated or rejected based on the ability of in silico models to accurately predict spatial and temporal patterns of tissue differentiation observed experimentally. The goal of this study was to employ a previously developed computational framework to test the hypothesis that substrate stiffness and oxygen availability regulate stem cell differentiation during tissue regeneration within an implanted bone chamber. To enable a prediction of the oxygen levels within the bone chamber, a lattice model of angiogenesis was implemented where blood vessel progression was dependent on the local mechanical environment. The model successfully predicted key aspects of MSC differentiation, including the correct spatial development of bone, marrow and fibrous tissue within the unloaded bone chamber. The model also successfully predicted chondrogenesis within the chamber upon the application of mechanical loading. This study provides further support for the hypothesis that substrate stiffness and oxygen availability regulate stem cell differentiation in vivo. These simulations also highlight the indirect role that mechanics may play in regulating MSC fate by inhibiting blood vessel progression and hence disrupting oxygen availability within regenerating tissues.
\end{abstract}




\section{Introduction}

While it is well established that soluble factors, such as transforming growth factor beta (TGF- $\beta$ ) (Joyce et al. 1990) and bone morhogenetic proteins (BMPs) (Bostrom et al. 1995), regulate mesenchymal stem cell (MSC) differentiation during tissue regeneration, it is becoming increasingly clear that mechanical cues also play a key role in determining the fate of such cells. Mechanical stimuli such as tissue deformation, fluid flow and hydrostatic pressure are often implicated as regulators of tissue differentiation in vivo (Carter et al. 1988; Claes and Heigele 1999; Prendergast et al. 1997). In addition, in vitro studies have identified several other physical and biochemical environmental stimuli as key regulators of MSC differentiation. For example, the stiffness of the local matrix has been shown to be intimately linked to MSC differentiation, where an osteogenic phenotype is promoted by a stiff substrate, while adipogenesis is enhanced by exposure to a soft substrate (Engler et al. 2006; Park et al. 2011; Dupont et al. 2011). Oxygen availability is another known regulator of MSC differentiation (Holzwarth et al. 2010; Fehrer et al. 2007; Yun et al. 2002; Kanichai et al. 2008; Meyer et al. 2010; Hirao et al. 2006). Both adipogenesis and osteogenesis have been shown to be diminished under low oxygen conditions (Holzwarth et al. 2010; Fehrer et al. 2007; Yun et al. 2002), whereas chondrogenesis is promoted by hypoxia (Kanichai et al. 2008; Meyer et al. 2010; Hirao et al. 2006).

One of the main challenges associated with in vivo studies of stem cell fate is to accurately isolate and relate specific environmental stimuli to the temporal and spatial patterns of differentiation that occur during development or tissue regeneration. In silico studies can be used to predict the state of the local environment experienced by stem cells during complex developmental or regenerative events. As such, hypotheses for how MSC differentiation is regulated in vivo can be either corroborated or rejected based on the ability of in silico models to accurately predict spatial and temporal patterns of tissue differentiation observed experimentally (Carter et al. 1988; Claes and Heigele 1999; Prendergast et al. 1997; Lacroix and Prendergast 2002; Kelly and Prendergast 2005; Loboa et al. 2001; Geris et al. 2003; Khayyeri et al. 2009). For example, fracture repair, having been studied experimentally for decades, is probably the most extensively employed regenerative event for testing hypotheses for how various environmental factors regulate MSC differentiation. Hypotheses where tissue differentiation is regulated by mechanical stimuli (Lacroix and Prendergast 2002; Prendergast et al. 1997; Carter et al. 1988; Claes and Heigele 1999; Isaksson et al. 2006; Gomez-Benito et al. 2005), biochemical factors (Geris et al. 2008; Geris et al. 2010a; Peiffer et al. 2011) or a combination of oxygen availability and substrate stiffness (Burke and Kelly 2012; Burke et al. 2013) have all been partially corroborated by comparing model predictions of fracture repair to experimental observations. However, a robust test of a given hypothesis requires undertaking multiple experiments attempting to falsify the hypothesis. In the context of testing such tissue differentiation hypotheses within an in 
silico framework, the greater the number of scenarios in which the underlying model hypothesis is subjected to attempted falsifiability, but ultimately corroborated, the stronger the hypothesis becomes (Khayyeri et al. 2013).

It has been previously demonstrated that is it possible to simulate the temporal and spatial patterns of tissue differentiation during facture repair using a computational model where MSC differentiation is regulated by local oxygen availability and the stiffness of the surrounding substrate (Burke et al. 2013; Burke and Kelly 2012). To further test this bioregulatory theory, it is necessary to investigate if such a model could be used to successfully predict MSC differentiation during other regenerative events. The mechanically loaded bone chamber, as described by Tagil and Aspenberg (Tagil and Aspenberg 1999), provides a well-defined mechanical environment and has previously been shown suitable for testing the validity of tissue differentiation hypotheses (Khayyeri et al. 2011; Khayyeri et al. 2009; Geris et al. 2010b). Partial corroboration for a tissue differentiation model where MSC fate is regulated by octahedral shear strain and relative fluid velocity has previously been provided (Khayyeri et al. 2009). The model could successfully predict some important aspects of tissue differentiation within the chamber (for example cartilage formation upon the application of loading), but could not predict others such as fibrous tissue formation under unloaded conditions. Furthermore, this model did not incorporate a specific hypothesis for how environmental factors might impact the establishment of a marrow cavity. To enable the accurate simulation of the regenerative process inside the bone chamber, it was first sought to develop a model that could adequately describe the process of angiogenesis such that the local levels of oxygen within the bone chamber could be predicted. To this end a lattice-based model of angiogenesis capable of simulating blood vessel growth in both mechanically loaded and unloaded conditions was developed. This was coupled this with a previous theory of tissue differentiation (Burke and Kelly 2012) in a combined lattice and finite element based computational framework to test the hypothesis that substrate stiffness and oxygen availability regulate stem cell differentiation in vivo within an implanted bone chamber.

\section{Methods}

\subsection{Bone Chamber Experiment}

In the experimental study performed by Tagil and Aspenberg (Tagil and Aspenberg 1999), a threaded titanium chamber was formed from two semi-cylinders held in place by a hexagonal closed screw cap. The bottom end of the chamber was surgically screwed into the tibia of male Sprague-Dawley rats. Two openings at the implanted end allowed tissue ingrowth into the front of the chamber (Figure 1A). A mechanical stimulus was provided by a manually loaded piston (loaded group), whereas the 
unloaded group did not receive any mechanical stimulus. The loaded group wasn't subjected to any mechanical stimulus for the first 3 weeks of the study, followed by 6 consecutive weeks of loading. The unloaded group was not subjected to any loading for the duration of the 9 weeks. Full experimental details are available elsewhere (Tagil and Aspenberg 1999).

\subsection{Bone Chamber Finite Element Model}

A 3-dimensional FE model consisting of 14,200 finite elements was created to predict the mechanical environment within the inner bone chamber (Khayyeri et al. 2009; Tagil and Aspenberg 1999) (Figure 1B). Biphasic material properties were adopted (Table 1). The applied boundary conditions (Figure 1B) allowed fluid flow from ingrowth openings and also from the small area between the piston and the wall at the top (distal region) of the chamber, constrained radial displacements along the chamber walls and axial displacement at the chamber base. The described model was implemented into the commercial finite element software package MSC Marc (version 2008r1, MSC Software Corporation, Santa Ana, CA).

\subsection{Cell migration and proliferation}

Models of cell migration and proliferation were implemented using a lattice based approach. Within this approach, each finite element was discretised into a 3 dimensional lattice consisting of 1000 lattice points (10 points in each dimension) (Figure 2B). Each lattice point represented a potential position for a cell and its immediate extracellular matrix. All finite elements were cubic with side length of $0.1 \mathrm{~mm}$ giving each lattice point a spacing of $10 \mu \mathrm{m}$. Cell migration was implemented as a stochastic process by filling the allotted new cell position and vacating the previously filled position using random walk theory (Perez and Prendergast 2007; Byrne et al. 2011). Each cell attempted to migrate randomly into one of the adjoining lattice position. Should the adjoining cell position be occupied, the cell remains in its original position. Cell proliferation was implemented in a similar fashion by filling the allotted new cell position (with a "daughter" cell) while the previously filled position remained filled (with the "parent" cell). Migration/proliferation was limited only if the adjoining cell position is occupied. Phenotype specific migration $(M)$ and proliferation $(P)$ rates (Table 2) determined the number of attempted migration or proliferation actions per $12 \mathrm{~h}$ iteration (see Tissue Differentiation section for more information on iterative procedure). 30\% of cells positions in the ingrowth holes where initially filled with MSCs (Khayyeri et al. 2009). 5\% of all other cell positions up to the height of the ingrowth holes were also randomly filled with MSCs. MSCs could only differentiate once the minimum age for differentiation $\left(A g e_{d i f f}\right)$ was reached (Khayyeri et al. 2009) (Table 3). 


\section{$2.4 \quad$ Angiogenesis and oxygen transport}

Angiogenesis was also modelled using a lattice based approach, similar to Checa and Prendergast (2009) (Checa and Prendergast 2009), where capillaries were modelled as a consecutive sequence of lattice points filled with endothelial cells (Marlovits et al.). Vessel growth occurred at a constant rate $(V)$ (Table 3) and could occur in either a random direction or the previous direction of growth with equal probability. Endothelial cell death occurred where the local octahedral shear strain exceeded a threshold value ( $\gamma^{\text {angio }}$ ) (Table 3). Capillaries were permitted to branch and form new vessels, the probability of which occurring was a function of the length of the vessel. $L_{\min }$ represents the minimum length for a sprout to branch, while $L_{\max }$ represents the maximum length for a non-branching sprout (Table 3). Should two capillaries meet, anastmosis (fusion) occurred. Cell position in the ingrowth holes were initially filled with $30 \%$ endothelial cells as the initial source of blood vessels. Oxygen transport was simulated as a diffusive process, the boundary conditions of which were dependent upon the state of the blood supply (Burke and Kelly 2012; Burke et al. 2013). Similar to studies of other tissue regenerative events (Burke and Kelly 2012; Burke et al. 2013) and consistent with oxygen tension measurements inside a similar bone chamber experiment (Listrom et al. 1988), oxygen availability was initially assumed to be high in the chamber. As the simulation progressed, oxygen ( $\mathrm{O}_{2}$ ) diffused from blood vessels and was consumed at a rate calculated as the product of a cellular consumption rate $(Q)$ and cell density $(n)$ (see equation 1 below) (parameters used in the model of oxygen transport are available in Table 3). Cell density was determined from the number of filled lattice points at a given location.

$$
\frac{d O_{2}}{d t}=G \nabla^{2} O_{2}-Q n
$$

\subsection{Tissue Differentiation}

In this study, the process of MSC differentiation was regulated by substrate stiffness and oxygen availability (Burke and Kelly 2012) (Figure 2A). In brief, this theory proposed that osteogenesis and adipogenesis were inhibited in regions of hypoxia, while chondrogenesis was promoted is such a low oxygen environment (defined as regions in which the local oxygen drops below a threshold value $\left(\mathrm{O}_{2}\right.$ cartilage) (Table 3)). Where a sufficient oxygen supply existed, differentiation was regulated by the stiffness of the local substrate. A high substrate stiffness promoted osteogenesis, whereas low substrate stiffness promoted adipogenesis (It was further assumed that adipogenesis would further 
support the establishment of bone marrow). Fibrogenesis was predicted in regions of the chamber where none of these conditions were upheld.

The substrate stiffness stimulus at any point in the model is dependent upon the phenotype of surrounding lattice points. Engler et al refer to MSC differentiation regulated by the "elasticity of the microenvironment" of the cell (Engler et al. 2006). For example, the stiffness of osteoid matrix produced by osteoblasts is approximately $30 \mathrm{kPa}$, however, the stiffness of woven bone itself is orders of magnitude higher (in the order of GPa). In this tissue differentiation model, osteogenesis occurs when stem cells are adjacent to newly formed bone and hence in contact with osteoid as a substrate (and similarly for adipogenesis). In this implementation, specific threshold values of stiffness are therefore not required.

Tissue differentiation within the bone chamber was simulated via an iterative procedure (Figure 3). Within each iteration, a prediction of mechanical stimuli, cell phenotypes and densities, blood supply and oxygen availability is generated in order to enable the local phenotype predictions to be determined. Each iteration was 12 hours. In the computational model, a soft substrate stimulus was assumed along the base of the chamber which sits in the host marrow. The chamber walls were assumed to provide a stiff stimulus. Differentiated adipose tissue was also assumed to provide a soft substrate stimulus for further adipogenesis, while extracellular osteoid from differentiated osteoblasts was assumed to provide a stiff substrate stimulus for further osteogenesis. The process of endochondral ossification occurred in the model when a chondrocyte experienced a stiff (osteogenic) stimulus and the region was invaded by blood vessels. These (would-be hypertrophic) chondrocytes were removed through apoptosis to be replaced by the osteoblasts of the oncoming bone front. Fibroblasts subjected to an osteogenic stimulus also underwent apoptosis and new bone replaced the existing fibrous tissue (a process similar to intramembranous ossification where ossification initiates on a fibrous connective tissue membrane). Apoptosis occurred at a rate $D$ which determined the proportion of existing cells undergoing apoptosis in that particular iteration (Table 2). Different cell types synthesizing matrix of drastically different properties could exist within a single element, therefore a rule of mixtures was implemented to determine the properties of each element (Byrne et al. 2007). To prevent unphysiologically rapid changes in material properties, values were averaged over the last 10 iterations (Lacroix and Prendergast 2002). Also, should a finite element become dominated by one cell type (defined as at least $50 \%$ of the cell positions in an element which has a minimum of 100 cell positions occupied), other cell types within the element are also assumed to undergo apoptosis.

\section{$2.6 \quad$ Simulations}


As per experimental protocol (Tagil and Aspenberg 1999), tissue differentiation predictions in loaded and unloaded conditions were compared. Loading was simulated in the finite element model via the application of a pressure of $2 \mathrm{MPa}$ (Khayyeri et al. 2009) on the top surface of the ingrowing tissues. The pressure was applied via a linear ramp from 0 to $2 \mathrm{MPa}$ in $0.3 \mathrm{~s}$ followed by holding at $2 \mathrm{MPa}$ for a further 2.7s (Khayyeri et al. 2009). The time-course of both groups was computed in a series of 12 hour iterations (Figure 3). The bone chamber was initially assumed to be filled with granulation tissue. In each iteration, the progression of angiogenesis was simulated based on the prevailing local biophysical stimulus. Cells migrated, proliferated and depending on the calculated oxygen availability and substrate stiffness, the MSCs differentiated into different cell phenotypes. At the end of each iteration, the material properties of the bone chamber FEM were updated (see Figure 3). The timedependent tissue differentiation process inside the bone chamber was simulated for 9 weeks, following Tagil and Aspenberg's experimental protocol (Tagil and Aspenberg 1999).

The authors of the bone chamber experiments reported that a dichotomous result was observed histologically for the loaded case (Tagil and Aspenberg 1999). In approximately half the loaded cases, cartilage was not observed. Additional simulations were performed with altered model parameters to investigate several possible explanations for such a dichotomy. It is possible that MSC density may be different in the marrow of different animals. It is also possible that as pressure was applied manually through the experiments, variability in the magnitude of this stimulus may have occurred. As a result, simulations were performed with altered MSC density $(20 \%, 30 \%, 50 \%)$ and varied magnitude of applied pressure at the top of the cortex (1MPa, 2MPa, 3MPa) to investigate such potential mechanisms. It was assumed in the experiment that the ingrowth holes lay fully in the marrow cavity, but it may be possible that the upper cortex restricts MSC access to the chamber (that normally occurs via the ingrowth holes). Therefore, a simulation with partially blocked ingrowth holes was also performed (where the upper 1/3 of ingrowth holes were blocked to simulate potential inconsistent implant positioning during surgery).

\section{Results}

Predominately fibroblastic differentiation was predicted within the bone chamber during the first three weeks of the study when no external mechanical loading was applied (Figure 4 and Figure 6). Osteogenic and adipogenic differentiation was initially predicted to be confined to areas immediately adjacent to the chamber holes, with increased adipogenesis by week 3 . Early osteogenic differentiation was predicted to occur primarily along the chamber walls, firstly in the regions around the ingrowth holes at the front of the chamber and then progressing toward the back region of the chamber. Adipogenesis were predicted more homogeneously along the proximal (bottom) region of 
the chamber but again began at the front of the chamber progressing towards the back (Figure 5). Blood vessels progressed in a random fashion from the ingrowth holes to fill the majority of the proximal region of the chamber by the end of week 3, with the exception being a region at the back of the chamber which remained unserved by vessels. As no mechanical loading was applied for the first three weeks, similar predictions were made for the loaded and unloaded cases during this time period.

From week 3 to week 6, new osteoblasts and adipocytes were predicted to occupy a larger part of the unloaded bone chamber (Figure 4 and Figure 6). Osteoblasts were predicted to spread radially inwards from the walls towards the centre of the chamber (Figure 5 and Figure 7). Osteoblastic differentiation was also predicted in more distal regions of the chamber, but bone was still more prominent closer to the ingrowth holes than the back of the chamber (Figure 4 and Figure 6). Homogenous adipogenic differentiation was predicted in the proximal region of the chamber. An increase in fibroblastic differentiation was predicted in the distal region of the chamber, with apoptosis of fibroblasts predicted in the proximal region of the chamber. All of this was similar for both loaded and unloaded cases. A small number of MSCs were predicted to differentiate into chondrocytes in the upper (distal) regions of the chamber for the loaded case. Such chondrogenesis was not predicted in the unloaded case. In the unloaded case, blood vessels were predicted to fill the remaining empty regions at the back of the chamber and to also progress further up the chamber. In the loaded case, this progression into the back and distal regions of the chamber was predicted to be much slower.

At the end of the 9 week simulated period, osteoblasts were predicted to bridge across the centre of the chamber. In the lower chamber osteoblasts primarily existed along the chamber walls (Figure 4 and Figure 6). At the end of the 9 week simulation, the total amounts of each tissue type within the chamber were computed (Figure 8). There was slightly more bone predicted to form in the unloaded case $(36.8 \%$ versus $31.8 \%$ observed experimentally), with osteoblastic differentiation predicted further up the chamber also. By week 9, adipogenesis was predicted almost homogeneously across the proximal region of the chamber, with new marrow tissue making up $34.8 \%$ and $33.2 \%$ of the neotissue within the chamber for the unloaded and loaded cases respectively (Table 4 and Figure 8). Fibroblasts were predicted to persist in the distal regions of the chamber, but underwent apoptosis and were replaced by osteoblasts and adipocytes in lower regions of the chamber for both loaded and unloaded cases (Figure 5 and Figure 7). Blood vessels approached the distal region in the loaded case, but in the unloaded case extend further up into the chamber. Greater levels of chondrogenesis were predicted in the distal regions of the loaded chamber, with cartilage making up approx $2.5 \%$ of total tissue content by at week 9 (Table 4 and Figure 8). No cartilage was predicted in the unloaded case.

The effect of parameter variations theorised as possible explanations for the dichotomous result observed experimentally (Tagil and Aspenberg 1999; Khayyeri et al. 2009) in the loaded case is summarised here (data not shown). Decreasing the magnitude of applied pressure to $1 \mathrm{MPa}$ from 
$2 \mathrm{MPa}$ for the loaded case resulted in very little change in differentiation because a similar sized region of high strain suppressing angiogenesis was still predicted. Increasing the magnitude from $2 \mathrm{MPa}$ to $3 \mathrm{MPa}$ led to slightly more blood vessel inhibition in the distal regions of the chamber and hence a small increase in the number of chondrocytes and a small decrease in the number of osteoblasts predicted. Altered implant positioning resulted in all tissues forming lower down in the chamber. Partially blocking the holes in the proximal end of the chamber was predicted to increase adipogenic differentiation and reduce fibrogenic differentiation. Chondrogenic differentiation was still predicted in a similar quantity to the baseline simulation. Increased initial MSC density (from $30 \%$ to $50 \%$ ) results in increased chondrogenic differentiation as a result of higher cellular oxygen consumption. Other tissue type predictions remained similar in terms of both positioning and tissue fraction percentage. Decreased initial MSC density (from 30\% to 20\%) predicts delayed and decreased chondrogenic differentiation with all other tissue fractions remaining similar. Also, the majority of tissue formation occurred more towards the proximal end of the chamber.

\section{Discussion}

In vitro studies have identified biochemical cues (Knippenberg et al. 2006; Pittenger et al. 1999), mechanical signals such as hydrostatic pressure and tissue deformation (Haudenschild et al. 2009; Takahashi et al. 1998), as well as substrate stiffness (Engler et al. 2006; Park et al. 2011) and oxygen availability (Holzwarth et al. 2010; Fehrer et al. 2007; Yun et al. 2002; Kanichai et al. 2008; Meyer et al. 2010; Hirao et al. 2006) as regulators of MSC differentiation. Identifying relationships between such stimuli and temporal and spatial patterns of tissue differentiation using in vivo experiment alone is complex, expensive and often impractical. In silico studies provide a mechanism for testing a given tissue differentiation hypotheses by means of 'trial and error' (van der Meulen and Huiskes 2002), whereby a given hypothesis is either corroborated or rejected based on its ability to successfully predict patterns of tissue differentiation during regenerative events. The implanted bone chamber provides a suitable regenerative event for attempted corroboration of tissue differentiation theories using such in silico approaches. This study employed a computational framework in which tissue differentiation is regulated by substrate stiffness and oxygen availability (Burke and Kelly 2012), in an attempt to predict MSC fate in vivo within an implanted bone chamber (Tagil and Aspenberg 1999). Predictions from the model provide partial corroboration for the hypothesis that tissue differentiation during such regenerative events is regulated, at least in part, by the local substrate stiffness and oxygen availability, providing further support for the key role that such stimuli play in regulating MSC fate in vivo.

During the early stages of regeneration, the model predicted only small amounts of osteogenic differentiation (Figure 4 and Figure 6). Osteogenesis was predicted predominantly along the chamber 
walls, which provide the required stiff substrate for differentiation to proceed along this pathway. Such osteogenic differentiation along the chamber walls is also observed histologically (Tagil and Aspenberg 1999; Khayyeri et al. 2009). Higher levels of adipogenesis than osteogenesis were predicted in the early stages of the simulation, with expansion of the existing host marrow into the proximal region of the chamber. As both adipogenesis and osteogenesis were assumed to depend on the existence of a blood supply, differentiation of MSCs towards adipocytes and osteocytes was initially predicted in greater numbers in regions adjacent to the ingrowth holes, advancing towards the back regions of the chamber as vessels progressed. A large number of fibroblasts were predicted in the chamber during the early stages of the study as the level of oxygen did not drop sufficiently to provide the hypoxic conditions necessary for chondrogenesis. (These predictions were similar for both loaded and unloaded cases as loading only begins 3 weeks post-implantation. The stochastic nature of cell migration and proliferation as well as blood vessel growth directionality results in every simulation being slightly different).

Six weeks post-implantation, a relatively small number of chondrocytes were predicted above the bony layer for the loaded case. This was due to mechanical loading causing high strains in the distal part of the chamber, which delays or prevents blood vessel progression into this region of the chamber (Figure 6 and Figure 7). The presence of large numbers of cells in a region not served by blood vessels resulted in the development of hypoxic conditions locally within the bone chamber, which in turn promoted chondrogenesis. In the unloaded case, no such mechanical inhibition of blood vessel growth occurred and hence blood vessels filled more of the distal region of the chamber (Figure 4 and Figure 5). Such vessels provided enough oxygen to prevent the development of a hypoxic region and hence chondrogenic differentiation did not occur.

After the full nine week term, chondrogenic differentiation increased in the loaded case due to continued blood vessel disruption (and hence the development of larger hypoxic regions) caused by the excessive strains in the distal regions of the chamber (Figure 6 and Figure 7). There was again no vessel disruption in the unloaded case, allowing vessels to progress further up the chamber and thereby preventing the development of hypoxic regions and subsequent chondrogenesis (Figure 4 and Figure 5). This is in agreement with experimental observations of cartilage formation in the loaded case and none in the unloaded case (Tagil and Aspenberg 1999). The cartilage in the loaded case was also predicted to form in the correct spatial location above the bone layer, and in similar amounts to that observed experimentally (3.3\% observed experimentally compared to $2.5 \%$ predicted by the model, see Table 4). Less osteogenic differentiation was predicted in the loaded case due to inhibition of blood vessel growth. This is also in agreement with experimental observations (Figure 8 and Table 4). Experimentally there was less marrow formation observed in the loaded case, however the simulations only predicted a small difference. Fibroblastic differentiation was predicted in the distal 
region of the chamber above a layer of bone, which again agrees with histology for both the loaded and unloaded cases.

Partial corroboration for an alternative tissue differentiation model where MSC fate is regulated by octahedral shear strain and relative fluid velocity has also previously been provided by attempting to simulate the time course of tissue formation within the same implanted bone chamber modelled in this study (Khayyeri et al. 2009). In that case, simulations were not completely predictive of the unloaded experiment. For example, a chamber filled with bone was predicted after 9 weeks, with a prediction of little or no fibrous tissue formation. This occurred because fibrous tissue formation could only occur under the direct application of load in that model. The tissue differentiation model in question (Prendergast et al. 1997) does not include a specific stimulus for adipogenesis and therefore does not enable prediction of experimentally observed adipose cells in the marrow cavity under either loading conditions. In contrast, the model governed by substrate stiffness and oxygen availability includes adipogenesis and fibrous tissue formation without the direct influence of mechanical loading, and was thus able to predict fibrous tissue formation above the bony region as well as adipose cells beneath the bony bridge. (Figure 4 and Figure 5).

The mechano-regulation model based on strain and fluid velocity was predictive of the spatial and temporal patterns of cartilage formation in the loaded case (Khayyeri et al. 2009), which was also successfully predicted by our model regulated by substrate stiffness and oxygen availability. However, differences do occur between the model predictions in terms of the primary method of bone formation within the loaded chambers. Both models predicted bone formation in the unloaded phase by intramembranous ossification. Differences were predicted upon the application of loading after 3 weeks. The model in this study predicts endothelial cell necrosis upon loading, leading to a decrease in progression of bone up the chamber. Osteogenesis was predicted to slow but with continued formation via intramembranous ossification with only small amounts of endochondral bone formation. This is contrary to the previous model (Prendergast et al. 1997) (regulated by shear strain and fluid velocity) which predicted apoptosis of the intramembranous bone upon load application. New bone then formed primarily via the endochondral ossification process (differentiation of MSCs into chondrocytes before they are replaced with osteoblasts) rather than through the intramembranous route predicted in this study. Without extra experimental data on spatial tissue distributions from earlier time points, it is impossible to distinguish which model is more accurate in its predictions of the mechanisms of bone formation in vivo. The fact that neither underlying hypothesis for MSC differentiation can be fully falsified by simulating this particular experiment points to the need for further work to elucidate the specific roles of particular environmental cues in regulating stem cell fate in vivo. 
There are some limitations associated with the model. Firstly, a dichotomy was observed in the experimental results, with cartilage only being observed in approximately half the cases where mechanical loading was applied, but not being observed in the other cases. Changes in MSC density, loading magnitude or partially blocked ingrowth holes did not lead to a simulation prediction of no cartilage for the loaded case. However, decreased initial MSC density predicted delayed and decreased chondrogenic differentiation, suggesting that this may play a role in explaining the dichotomous result observed experimentally. This dichotomy in the loaded case may also be at least partially explained by variable mechanosensitivity among animals. This was posed as a possible explanation by Khayyeri et al following a study which could predict aspects of both sides of the dichotomy by varying model parameters referring to mechanosensitivity (Khayyeri et al. 2011). There are also some other limitations associated with the present study. The model of angiogenesis employed in this study does not consider chemotaxis which can bias blood vessel growth directionality towards a source of VEGF for example (Street et al. 2002). Chemotaxis has been implemented in similar lattice models of angiogenesis (Checa and Prendergast 2009; Reina-Romo et al. 2012) with blood vessel directionality biased towards VEGF which was assumed to be secreted by hypertrophic chondrocytes. It is unlikely that such an addition would significantly influence simulation predictions as chondrocytes are small in number and are predicted in regions where blood vessels are likely to be inhibited by high shear strains. Blood vessel growth rate was assumed constant and independent of strain which is another simplification of the model of angiogenesis. The model contains many parameters obtained from the literature and includes some simplifications of complex biological processes such as cellular migration and proliferation which may result in deviations in model predictions from experimental observations. It should also be noted that a simplified model of bone marrow reestablishment has been implemented in this study. The authors recognize that the marrow of the medullary cavity of long bones contains not only the marrow stroma and adipose tissue predicted by our algorithm, but also hematopoietic and lymphatic cells. Again, these simplifications were implemented to enable us to test the hypothesis of the study without introducing additional complexity. The simplified nature of this aspect of the model may contribute to the fact that the simulations did not predict the same reduction in marrow formation within the bone chamber with the application of loading as is observed experimentally. A further model limitation is that all cell sizes are assumed to be exactly that of a lattice position which is not representative of the biological reality. In addition, the generation of necrotic tissue is not considered in the model but is observed experimentally. Finally, the process of bone resorption is not accounted for in the model.

In conclusion, previous studies have postulated a direct role for mechanics in regulating MSC differentiation during tissue regeneration. This work points to the indirect role that mechanics may play in regulating MSC fate by inhibiting (mechano-regulated) blood vessel progression and hence disrupting oxygen availability within regenerating tissues. The study therefore provides further 
support for the hypothesis that substrate stiffness and oxygen availability at least partially regulate stem cell differentiation in vivo. This tissue differentiation hypothesis has therefore been further corroborated by simulating multiple different regenerative events (Burke et al. 2013; Burke and Kelly 2012) thereby strengthening its validity and utility.

\section{Acknowledgements}

Funding provided by a Science Foundation Ireland President of Ireland Young Researcher Award (08/Y15/B1336), a European Research Council Starter Grant (Stem Repair - No. 258463) and through a Trinity College Dublin Research Studentship Award.

\section{Figure Legends}

Figure 1. (A) Cross section of the implanted bone chamber. Red arrows point to the ingrowth openings and the grey arrow indicates the direction of applied pressure (Adapted from (de Rooij et al. 2001) with permission). (B) Finite element model of the implanted bone chamber. The displacement in outer chamber was constrained in the $\mathrm{x}$ and $\mathrm{y}$ directions (thin dotted line). Displacement at the base of the chamber was constrained in $\mathrm{x}, \mathrm{y}$ and $\mathrm{z}$ directions (thicker dotted line). Free fluid flow boundary conditions were applied at the top of the chamber (to represent the gap between piston and chamber wall) and at the ingrowth holes (blue arrows).

Figure 2. (A) Tissue differentiation regulated by substrate stiffness and oxygen availability. The oxygen availability axis extends radially from the centre of the circle, low oxygen in the centre of the circle increasing towards the periphery. The substrate stiffness axis extends circumferentially in a clockwise direction from the right side of the dotted line at the top of the circle. The presence of a blood supply is also a prerequisite for formation of bone and marrow. (B) A 3 dimensional finite element with corresponding lattice. Each lattice point represents a potential location for a cell and its immediate extracellular matrix.

Figure 3. Iterative procedure for generating temporal and spatial predictions of tissue differentiation.

Figure 4. Unloaded case tissue differentiation predictions for 3, 6 and 9 week time points (side elevation view). Results are presented as a cross section from front to back of chamber (see red slice of schematic on right of figure). Bottom Right: Simplified histology results from experimental study (Tagil and Aspenberg 1999) (Adapted from (Khayyeri et al. 2009) with permission). (CH: Chondrocytes, OB: Osteoblasts, AD: Adipocytes, FB: Fibroblasts, EC: Endothelial cells). 
Figure 5. Unloaded case tissue differentiation predictions for 3, 6 and 9 week time points (plan view). Results are presented for heights of $2.5 \mathrm{~mm}$ (Topol et al.), $1.5 \mathrm{~mm}$ (middle) and $2.5 \mathrm{~mm}$ (bottom) (see red slice of schematics on right of figure). (CH: Chondrocytes, OB: Osteoblasts, AD: Adipocytes, FB: Fibroblasts, EC: Endothelial cells).

Figure 6. Loaded case tissue differentiation predictions for 3, 6 and 9 week timepoints (side elevation view). Results are presented as a cross section from front to back of chamber (see red slice of schematic on right of figure). Bottom Right: Simplified histology results from experimental study (Tagil and Aspenberg 1999) (Adapted from (Khayyeri et al. 2009) with permission). (CH: Chondrocytes, OB: Osteoblasts, AD: Adipocytes, FB: Fibroblasts, EC: Endothelial cells).

Figure 7. Loaded case tissue differentiation predictions for 3, 6 and 9 week timepoints (plan view). Results are presented for heights of $2.5 \mathrm{~mm}$ (Topol et al.), $1.5 \mathrm{~mm}$ (middle) and $2.5 \mathrm{~mm}$ (bottom) (see red slice of schematics on right of figure). (CH: Chondrocytes, OB: Osteoblasts, AD: Adipocytes, FB: Fibroblasts, EC: Endothelial cells).

Figure 8. Temporal tissue phenotype fractions for unloaded and loaded cases. 
Table 1 Material properties

\begin{tabular}{lllllll} 
Material Property & $\begin{array}{l}\text { Granulation } \\
\text { Tissue }\end{array}$ & $\begin{array}{l}\text { Fibrous } \\
\text { Tissue }\end{array}$ & Cartilage & Marrow & Bone & $\begin{array}{l}\text { Mature } \\
\text { Bone }\end{array}$ \\
\hline Young's Modulus (MPa) & $0.2^{\mathrm{a}}$ & $2^{\mathrm{b}}$ & $10^{\mathrm{a}}$ & $2^{\mathrm{a}}$ & $1,000^{\mathrm{a}}$ & $6,000^{\mathrm{c}}$ \\
Permeability (mm2) & $1 \mathrm{E}-11^{\mathrm{a}}$ & $1 \mathrm{E}-11^{\mathrm{b}}$ & $5 \mathrm{E}-15^{\mathrm{d}}$ & $1 \mathrm{E}-14^{\mathrm{a}}$ & $1 \mathrm{E}-13^{\mathrm{a}}$ & $3.7 \mathrm{E}-13^{\mathrm{e}}$ \\
Poisson's Ratio & $0.167^{\mathrm{a}}$ & $0.167^{\mathrm{a}}$ & $0.167^{\mathrm{a}}$ & $0.167^{\mathrm{a}}$ & $0.3^{\mathrm{a}}$ & $0.3^{\mathrm{a}}$ \\
Fluid Dynamic Viscosity (Ns/m2) & $1 \mathrm{E}-9$ & $1 \mathrm{E}-9$ & $1 \mathrm{E}-9$ & $1 \mathrm{E}-9$ & $1 \mathrm{E}-9$ & $1 \mathrm{E}-9$ \\
Porosity & $0.8^{\mathrm{a}}$ & $0.8^{\mathrm{a}}$ & $0.8^{\mathrm{a}}$ & $0.8^{\mathrm{a}}$ & $0.8^{\mathrm{a}}$ & $0.8^{\mathrm{a}}$
\end{tabular}

a. Lacroix and Prendergast (2002) (Lacroix and Prendergast 2002); b. Hori and Lewis (1982) (Hori and Lewis 1982); c. Claes and Heigele (1999) (Claes and Heigele 1999); d. Armstrong and Mow (1982) (Armstrong and Mow 1982); e. Ochoa and Hillberry (1992) (Ochoa and Hillberry 1992); f. Cowin 1999 (Cowin 1999); g. Schaffler and Burr (1988) (Schaffler and Burr 1988).

Table 2 Cell Model parameters

\begin{tabular}{llllll} 
Model Parameter & Fibroblasts & Chondrocytes & Adipocytes & Osteoblasts & MSCs \\
\hline Proliferation Rate $(1 / 2 \text { day })^{-1}$ & $0.27^{\mathrm{a}}$ & $0.1^{\mathrm{a}}$ & 0.2 & $0.15^{\mathrm{a}}$ & $0.3^{\mathrm{a}}$ \\
Migration Rate $(\mu \mathrm{m} / \mathrm{h})$ & $26.6^{\mathrm{b}}$ & N/A & 26.6 & N/A & $26.6^{\mathrm{b}}$ \\
Degradation Rate $(1 / 2 \text { day })^{-1}$ & $0.025^{\mathrm{a}}$ & $0.05^{\mathrm{a}}$ & 0.05 & $0.08^{\mathrm{a}}$ & $0.025^{\mathrm{a}}$ \\
Differentiation Rate $(1 / 2 \text { day })^{-1}$ & N/A & N/A & N/A & N/A & $0.15^{\mathrm{a}}$
\end{tabular}

a. Isaksson et al (2008) (Isaksson et al. 2008) ; b. Appeddu and Shur (1994) (Appeddu and Shur 1994). 
Table 3 Tissue Differentiation Model parameters

\begin{tabular}{|c|c|c|c|c|}
\hline Model Parameter & Symbol & Source & Unit & Value \\
\hline Strain Threshold for Angiogenic Inhibition & $\gamma^{\text {angio }}$ & (Burke and Kelly 2012) & $\%$ & 6 \\
\hline Blood Vessel Growth Rate & $V$ & Estimated & $\mu \mathrm{m} .(1 / 2 \text { day })^{-1}$ & 40 \\
\hline Minimum Length Branching & $L_{\min }$ & $\begin{array}{l}\text { (Checa and Prendergast } \\
\text { 2009) }\end{array}$ & $\mu \mathrm{m}$ & 100 \\
\hline Maximum Length (without) Branching & $L_{\max }$ & (Checa 2012) & $\mu \mathrm{m}$ & 300 \\
\hline Minimum Age for Differentiation & $A g e_{\text {diff }}$ & (Khayyeri et al. 2009) & days & 6 \\
\hline Oxygen Diffusion Coefficient & $G$ & $\begin{array}{l}\text { (Hershey and Karhan 1968; } \\
\text { Burke and Kelly 2012) }\end{array}$ & $\mathrm{m}^{2} / \mathrm{s}$ & 2.2E-09 \\
\hline Oxygen Consumption Rate & $Q$ & $\begin{array}{l}\text { (Pattappa et al. 2010; Burke } \\
\text { and Kelly 2012) }\end{array}$ & $\mathrm{fmol} / \mathrm{cell} / \mathrm{h}$ & 98 \\
\hline Initial Oxygen Tension & $\mathrm{O}_{2}{ }^{\text {initial }}$ & $\begin{array}{l}\text { (Epari et al. 2008; Burke } \\
\text { and Kelly 2012) }\end{array}$ & $\mathrm{mmHg}$ & 74.1 \\
\hline Oxygen Tension Limit for Cartilage & $\mathrm{O}_{2}^{\text {cartilage }}$ & $\begin{array}{l}\text { (Holzwarth et al. 2010; } \\
\text { Fehrer et al. 2007) }\end{array}$ & $\%$ & 3 \\
\hline
\end{tabular}

Table 4 Tissue Fractions from experimental analysis (Tagil and Aspenberg 1999; Khayyeri et al. 2009) and model predictions

$\begin{array}{lllll}\text { Bone } & \text { Cartilage } & \text { Marrow } & \text { Fibrous } & \text { Necrotic } \\ (\%) & (\%) & (\%) & \text { Tissue } & \text { Tissue } \\ & & & (\%) & (\%)\end{array}$

$\underline{\text { Experiment }}$

\begin{tabular}{lccccc} 
Unloaded & 31.0 & 0.0 & 38.6 & 30.4 & 0.0 \\
Loaded & 23.5 & 3.3 & 30.6 & 35.0 & 7.4 \\
Model Predictions & & & & & \\
Unloaded & 32.4 & 0.0 & 34.8 & 32.8 & 0.0 \\
Loaded & 27.6 & 2.5 & 33.2 & 36.7 & 0.0 \\
\hline
\end{tabular}




\section{References}

Appeddu PA, Shur BD (1994) Molecular analysis of cell surface beta-1,4-galactosyltransferase function during cell migration. Proceedings of the National Academy of Sciences of the United States of America 91 (6):2095-2099.

Armstrong CG, Mow VC (1982) Variations in the Intrinsic Mechanical Proterties of Human Articular-Cartilage with Age, Degeneration, and Water-Content. Journal of Bone and Joint Surgery-American Volume 64 (1):88-94.

Bostrom MP, Lane JM, Berberian WS, Missri AA, Tomin E, Weiland A, Doty SB, Glaser D, Rosen VM (1995) Immunolocalization and expression of bone morphogenetic proteins 2 and 4 in fracture healing. Journal of orthopaedic research : official publication of the Orthopaedic Research Society 13 (3):357-367.

Burke D, Dishowitz M, Sweetwyne M, Miedel E, Hankenson KD, Kelly DJ (2013) The role of oxygen as a regulator of stem cell fate during fracture repair in TSP2-null mice. Journal of orthopaedic research : official publication of the Orthopaedic Research Society.

Burke DP, Kelly DJ (2012) Substrate Stiffness and Oxygen as Regulators of Stem Cell Differentiation during Skeletal Tissue Regeneration: A Mechanobiological Model. PLoS One 7 (7):e40737.

Byrne DP, Lacroix D, Planell JA, Kelly DJ, Prendergast PJ (2007) Simulation of tissue differentiation in a scaffold as a function of porosity, Young's modulus and dissolution rate: application of mechanobiological models in tissue engineering. Biomaterials 28 (36):5544-5554.

Byrne DP, Lacroix D, Prendergast PJ (2011) Simulation of fracture healing in the tibia: Mechanoregulation of cell activity using a lattice modeling approach. J Orthop Res.

Carter DR, Blenman PR, Beaupre GS (1988) Correlations between mechanical stress history and tissue differentiation in initial fracture healing. J Orthop Res 6 (5):736-748.

Checa S, Byrne, D. P., Prendergast, P. J. (2012) Predictive modelling in mechanobiology: Combining algorithms for cell activities in response to physical stimuli using a lattice-modelling approach. Advanced Structured Materials 1 (1):423-435.

Checa S, Prendergast PJ (2009) A mechanobiological model for tissue differentiation that includes angiogenesis: a lattice-based modeling approach. Ann Biomed Eng 37 (1):129-145.

Claes LE, Heigele CA (1999) Magnitudes of local stress and strain along bony surfaces predict the course and type of fracture healing. J Biomech 32 (3):255-266.

Cowin SC (1999) Bone poroelasticity. J Biomech 32 (3):217-238.

de Rooij PP, Siebrecht MA, Tagil M, Aspenberg P (2001) The fate of mechanically induced cartilage in an unloaded environment. J Biomech 34 (7):961-966.

Dupont S, Morsut L, Aragona M, Enzo E, Giulitti S, Cordenonsi M, Zanconato F, Le Digabel J, Forcato M, Bicciato S, Elvassore N, Piccolo S (2011) Role of YAP/TAZ in mechanotransduction. Nature 474 (7350):179-183.

Engler AJ, Sen S, Sweeney HL, Discher DE (2006) Matrix Elasticity Directs Stem Cell Lineage Specification. Cell 126 (4):677-689.

Epari DR, Lienau J, Schell H, Witt F, Duda GN (2008) Pressure, oxygen tension and temperature in the periosteal callus during bone healing--an in vivo study in sheep. Bone 43 (4):734-739.

Fehrer C, Brunauer R, Laschober G, Unterluggauer H, Reitinger S, Kloss F, Gully C, Gassner R, Lepperdinger $\mathrm{G}$ (2007) Reduced oxygen tension attenuates differentiation capacity of human mesenchymal stem cells and prolongs their lifespan. Aging Cell 6 (6):745-757.

Geris L, Gerisch A, Sloten JV, Weiner R, Oosterwyck HV (2008) Angiogenesis in bone fracture healing: a bioregulatory model. J Theor Biol 251 (1):137-158.

Geris L, Sloten JV, Van Oosterwyck H (2010a) Connecting biology and mechanics in fracture healing: an integrated mathematical modeling framework for the study of nonunions. Biomechanics and Modeling in Mechanobiology 9 (6):713-724.

Geris L, Van Oosterwyck H, Vander Sloten J, Duyck J, Naert I (2003) Assessment of mechanobiological models for the numerical simulation of tissue differentiation around immediately loaded implants. Computer methods in biomechanics and biomedical engineering 6 (5-6):277-288. 
Geris L, Vandamme K, Naert I, Vander Sloten J, Van Oosterwyck H, Duyck J (2010b) Mechanical loading affects angiogenesis and osteogenesis in an in vivo bone chamber: a modeling study. Tissue Eng Part A 16 (11):3353-3361.

Gomez-Benito MJ, Garcia-Aznar JM, Kuiper JH, Doblare M (2005) Influence of fracture gap size on the pattern of long bone healing: a computational study. J Theor Biol 235 (1):105-119.

Haudenschild AK, Hsieh AH, Kapila S, Lotz JC (2009) Pressure and distortion regulate human mesenchymal stem cell gene expression. Ann Biomed Eng 37 (3):492-502.

Hershey D, Karhan T (1968) Diffusion coefficients for oxygen transport in whole blood. AIChE Journal 14 (6):969-972.

Hirao M, Tamai N, Tsumaki N, Yoshikawa H, Myoui A (2006) Oxygen tension regulates chondrocyte differentiation and function during endochondral ossification. J Biol Chem 281 (41):31079-31092.

Holzwarth C, Vaegler M, Gieseke F, Pfister SM, Handgretinger R, Kerst G, Muller I (2010) Low physiologic oxygen tensions reduce proliferation and differentiation of human multipotent mesenchymal stromal cells. BMC Cell Biol 11:11.

Hori RY, Lewis JL (1982) Mechanical properties of the fibrous tissue found at the bone-cement interface following total joint replacement. J Biomed Mater Res 16 (6):911-927.

Isaksson H, van Donkelaar CC, Huiskes R, Ito K (2006) Corroboration of mechanoregulatory algorithms for tissue differentiation during fracture healing: Comparison with in vivo results. J Orthop Res 24 (5):898-907.

Isaksson H, van Donkelaar CC, Huiskes R, Ito K (2008) A mechano-regulatory bone-healing model incorporating cell-phenotype specific activity. Journal of Theoretical Biology 252 (2):230246.

Joyce ME, Roberts AB, Sporn MB, Bolander ME (1990) Transforming growth factor-beta and the initiation of chondrogenesis and osteogenesis in the rat femur. The Journal of cell biology 110 (6):2195-2207.

Kanichai M, Ferguson D, Prendergast PJ, Campbell VA (2008) Hypoxia promotes chondrogenesis in rat mesenchymal stem cells: a role for AKT and hypoxia-inducible factor (HIF)-1alpha. J Cell Physiol 216 (3):708-715.

Kelly DJ, Prendergast PJ (2005) Mechano-regulation of stem cell differentiation and tissue regeneration in osteochondral defects. Journal of Biomechanics 38 (7):1413-1422.

Khayyeri H, Checa S, Tagil M, Aspenberg P, Prendergast PJ (2011) Variability observed in mechanoregulated in vivo tissue differentiation can be explained by variation in cell mechanosensitivity. Journal of Biomechanics 44 (6):1051-1058.

Khayyeri H, Checa S, Tagil M, Prendergast PJ (2009) Corroboration of mechanobiological simulations of tissue differentiation in an in vivo bone chamber using a lattice-modeling approach. J Orthop Res 27 (12):1659-1666.

Khayyeri H, Isaksson H, Prendergast PJ (2013) Corroboration of computational models for mechanoregulated stem cell differentiation. Computer methods in biomechanics and biomedical engineering.

Knippenberg M, Helder MN, Zandieh Doulabi B, Wuisman PI, Klein-Nulend J (2006) Osteogenesis versus chondrogenesis by BMP-2 and BMP-7 in adipose stem cells. Biochem Bioph Res Co 342 (3):902-908.

Lacroix D, Prendergast PJ (2002) A mechano-regulation model for tissue differentiation during fracture healing: analysis of gap size and loading. J Biomech 35 (9):1163-1171.

Listrom RD, Symington JM, Albrektsson T (1988) A bone chamber for investigation of gas pressure. Oxygen tension measured in rabbits. Acta orthopaedica Scandinavica 59 (4):454-458.

Loboa EG, Beaupre GS, Carter DR (2001) Mechanobiology of initial pseudarthrosis formation with oblique fractures. Journal of orthopaedic research : official publication of the Orthopaedic Research Society 19 (6):1067-1072.

Marlovits S, Zeller P, Singer P, Resinger C, Vecsei V (2006) Cartilage repair: generations of autologous chondrocyte transplantation. Eur J Radiol 57 (1):24-31.

Meyer EG, Buckley CT, Thorpe SD, Kelly DJ (2010) Low oxygen tension is a more potent promoter of chondrogenic differentiation than dynamic compression. J Biomech 43 (13):2516-2523.

Ochoa JA, Hillberry BM (1992) Permeability of bovine cancellous bone. Trans of the 38th ORS:162. 
Park JS, Chu JS, Tsou AD, Diop R, Tang Z, Wang A, Li S (2011) The effect of matrix stiffness on the differentiation of mesenchymal stem cells in response to TGF-beta. Biomaterials 32 (16):3921-3930.

Pattappa G, Heywood HK, de Bruijn JD, Lee DA (2010) The metabolism of human mesenchymal stem cells during proliferation and differentiation. J Cell Physiol.

Peiffer V, Gerisch A, Vandepitte D, Van Oosterwyck H, Geris L (2011) A hybrid bioregulatory model of angiogenesis during bone fracture healing. Biomech Model Mechanobiol 10 (3):383-395.

Perez MA, Prendergast PJ (2007) Random-walk models of cell dispersal included in mechanobiological simulations of tissue differentiation. Journal of Biomechanics 40 (10):2244-2253.

Pittenger MF, Mackay AM, Beck SC, Jaiswal RK, Douglas R, Mosca JD, Moorman MA, Simonetti DW, Craig S, Marshak DR (1999) Multilineage Potential of Adult Human Mesenchymal Stem Cells. Science 284 (5411):143-147.

Prendergast PJ, Huiskes R, Soballe K (1997) ESB Research Award 1996. Biophysical stimuli on cells during tissue differentiation at implant interfaces. J Biomech 30 (6):539-548.

Reina-Romo E, Gomez-Benito MJ, Dominguez J, Garcia-Aznar JM (2012) A lattice-based approach to model distraction osteogenesis. Journal of Biomechanics 45 (16):2736-2742.

Schaffler MB, Burr DB (1988) Stiffness of compact bone: effects of porosity and density. J Biomech 21:13-16.

Street J, Bao M, deGuzman L, Bunting S, Peale FV, Jr., Ferrara N, Steinmetz H, Hoeffel J, Cleland JL, Daugherty A, van Bruggen N, Redmond HP, Carano RA, Filvaroff EH (2002) Vascular endothelial growth factor stimulates bone repair by promoting angiogenesis and bone turnover. Proc Natl Acad Sci U S A 99 (15):9656-9661.

Tagil M, Aspenberg P (1999) Cartilage induction by controlled mechanical stimulation in vivo. J Orthop Res 17 (2):200-204.

Takahashi I, Nuckolls GH, Takahashi K, Tanaka O, Semba I, Dashner R, Shum L, Slavkin HC (1998) Compressive force promotes sox9, type II collagen and aggrecan and inhibits IL-1beta expression resulting in chondrogenesis in mouse embryonic limb bud mesenchymal cells. $\mathbf{J}$ Cell Sci 111 ( Pt 14):2067-2076.

Topol L, Chen W, Song H, Day TF, Yang Y (2009) Sox9 inhibits Wnt signaling by promoting betacatenin phosphorylation in the nucleus. The Journal of biological chemistry 284 (5):33233333.

van der Meulen MC, Huiskes R (2002) Why mechanobiology? A survey article. Journal of Biomechanics 35 (4):401-414.

Yun Z, Maecker HL, Johnson RS, Giaccia AJ (2002) Inhibition of PPAR[gamma]2 Gene Expression by the HIF-1-Regulated Gene DEC1/Stra13: A Mechanism for Regulation of Adipogenesis by Hypoxia. Developmental Cell 2 (3):331-341. 


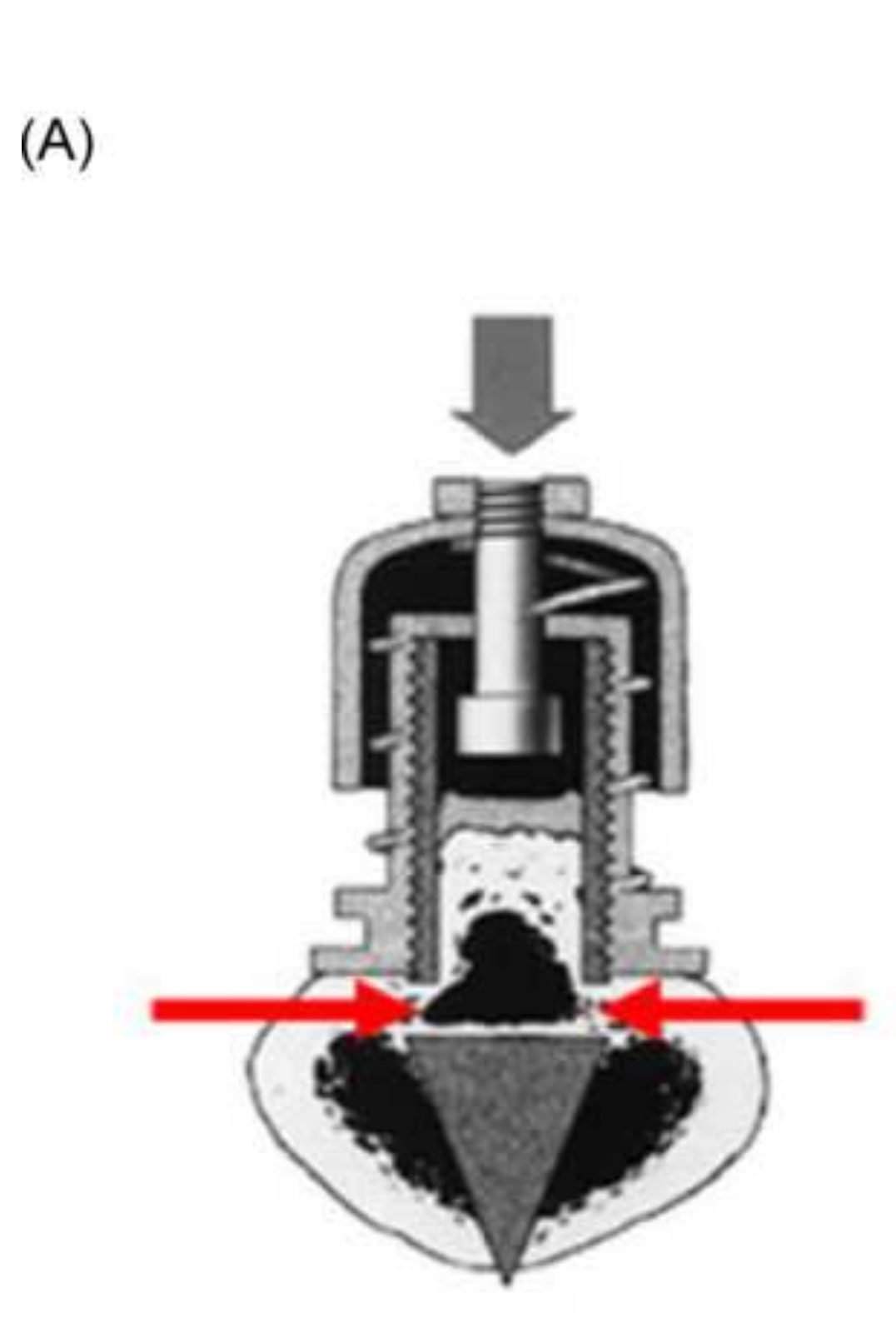

(A)
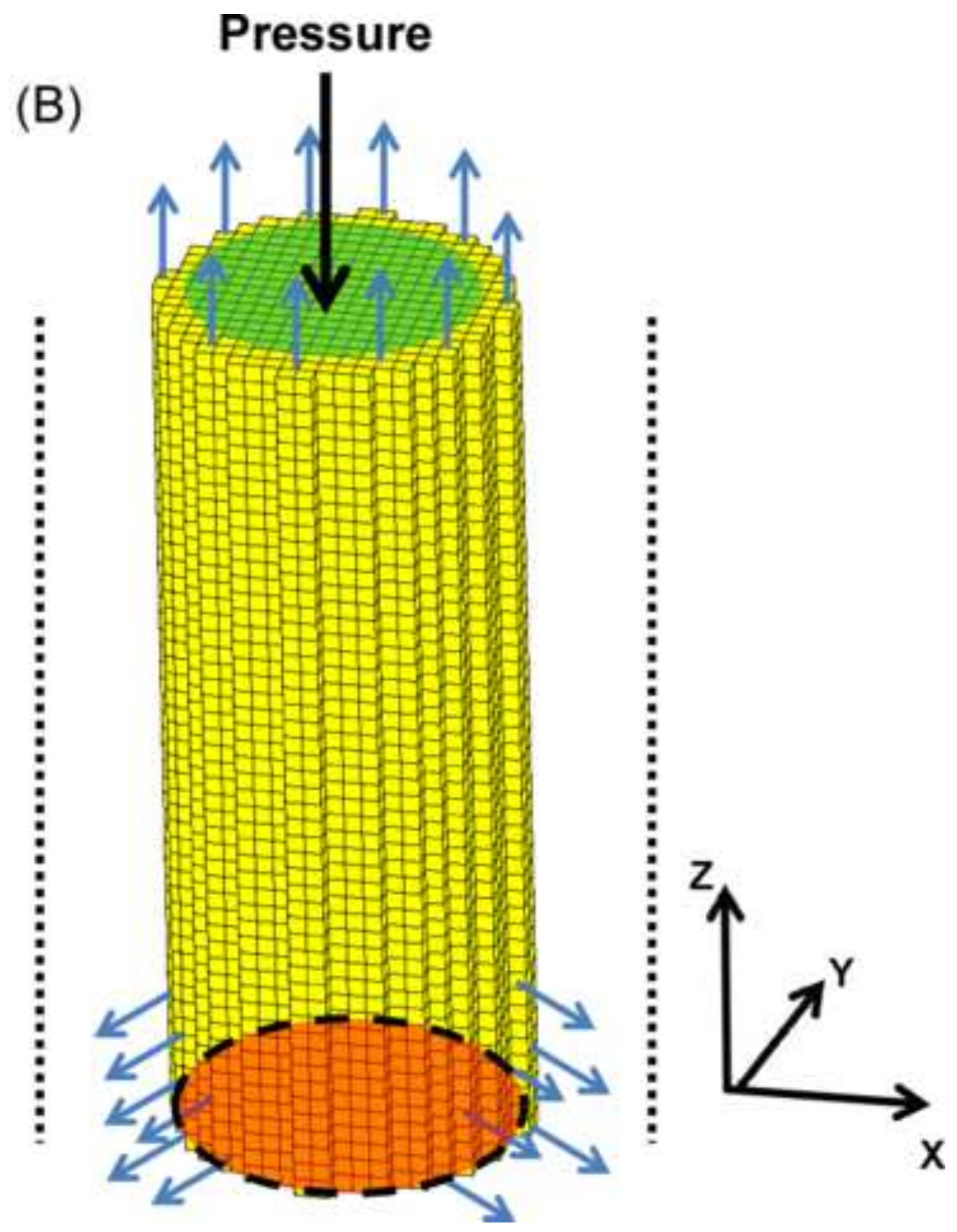

(B)

\section{Pressure}


(A) Substrate Stiffness

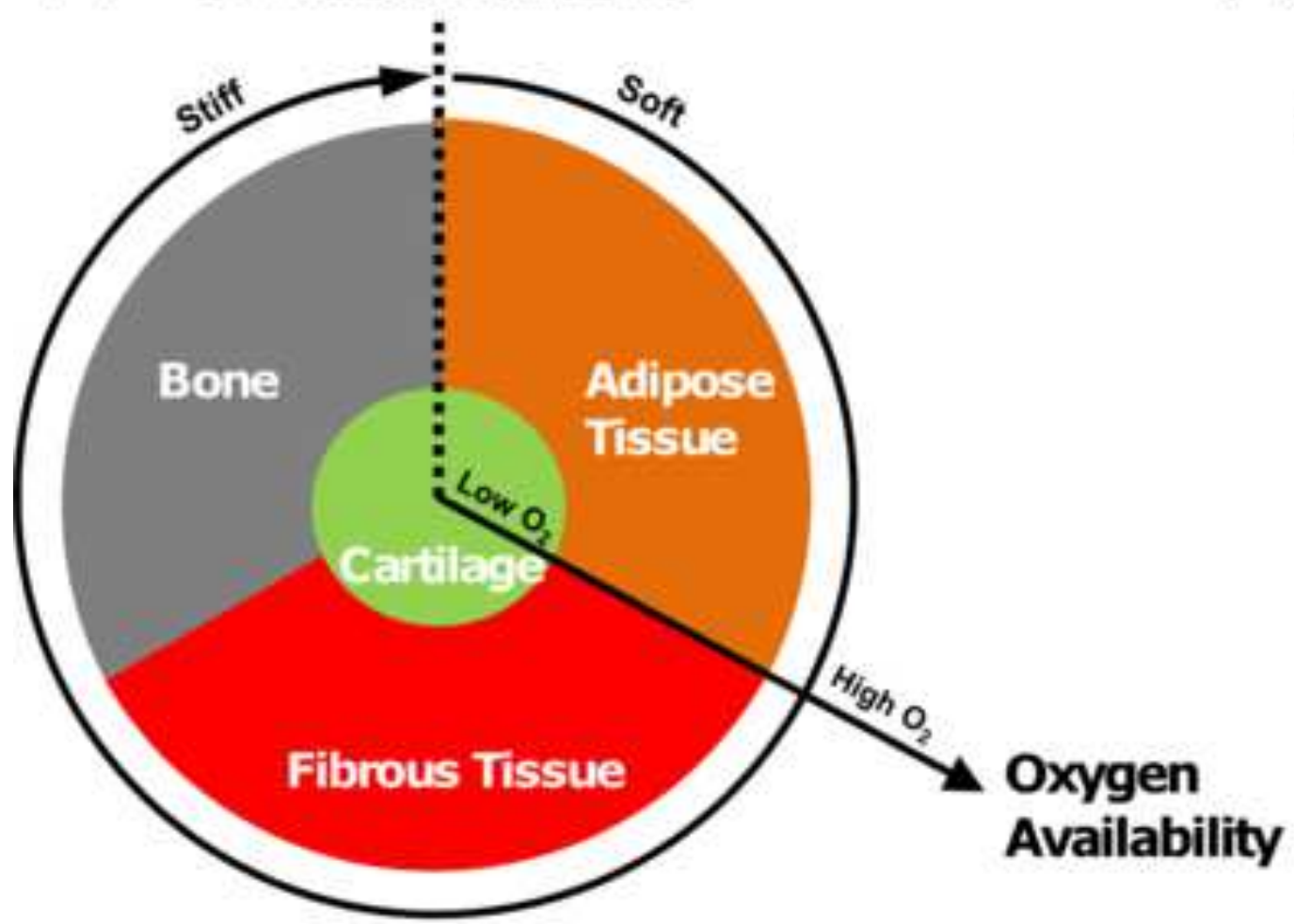

(B)

\section{Finite Element}

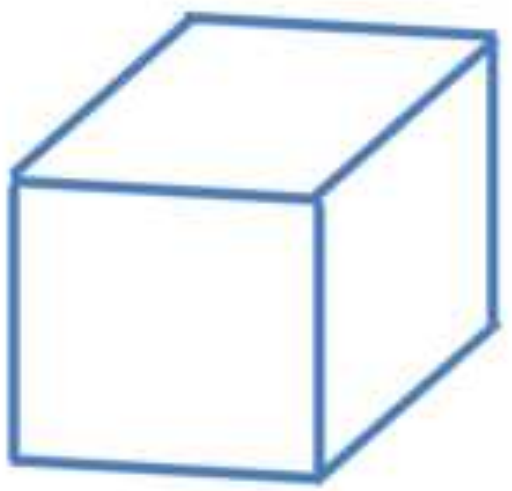

\section{Lattice}

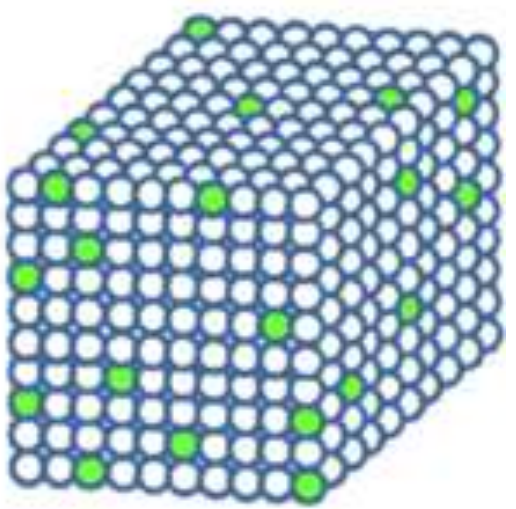

Filled Cell Position

Empty Cell Position 
Click here to download high resolution image

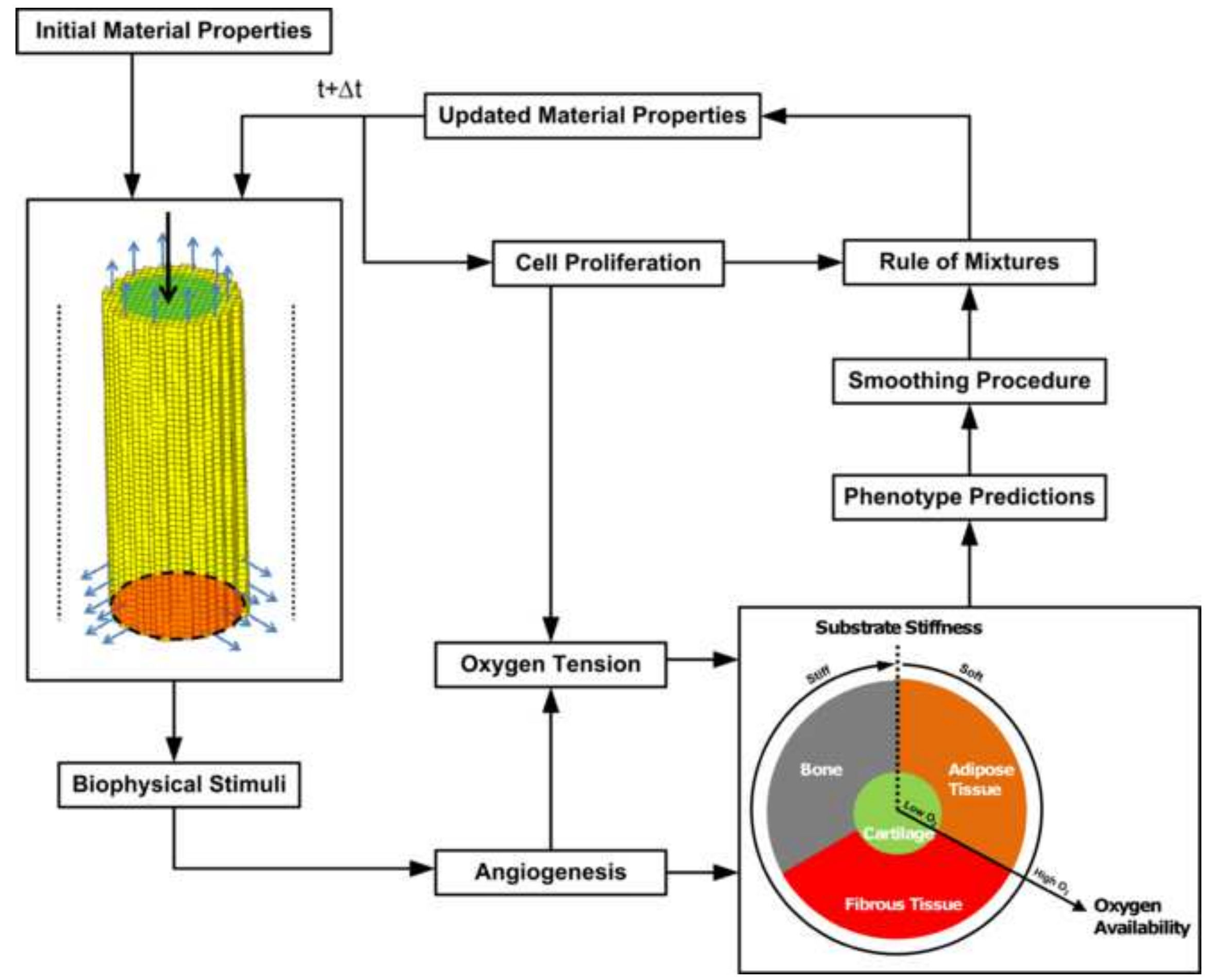




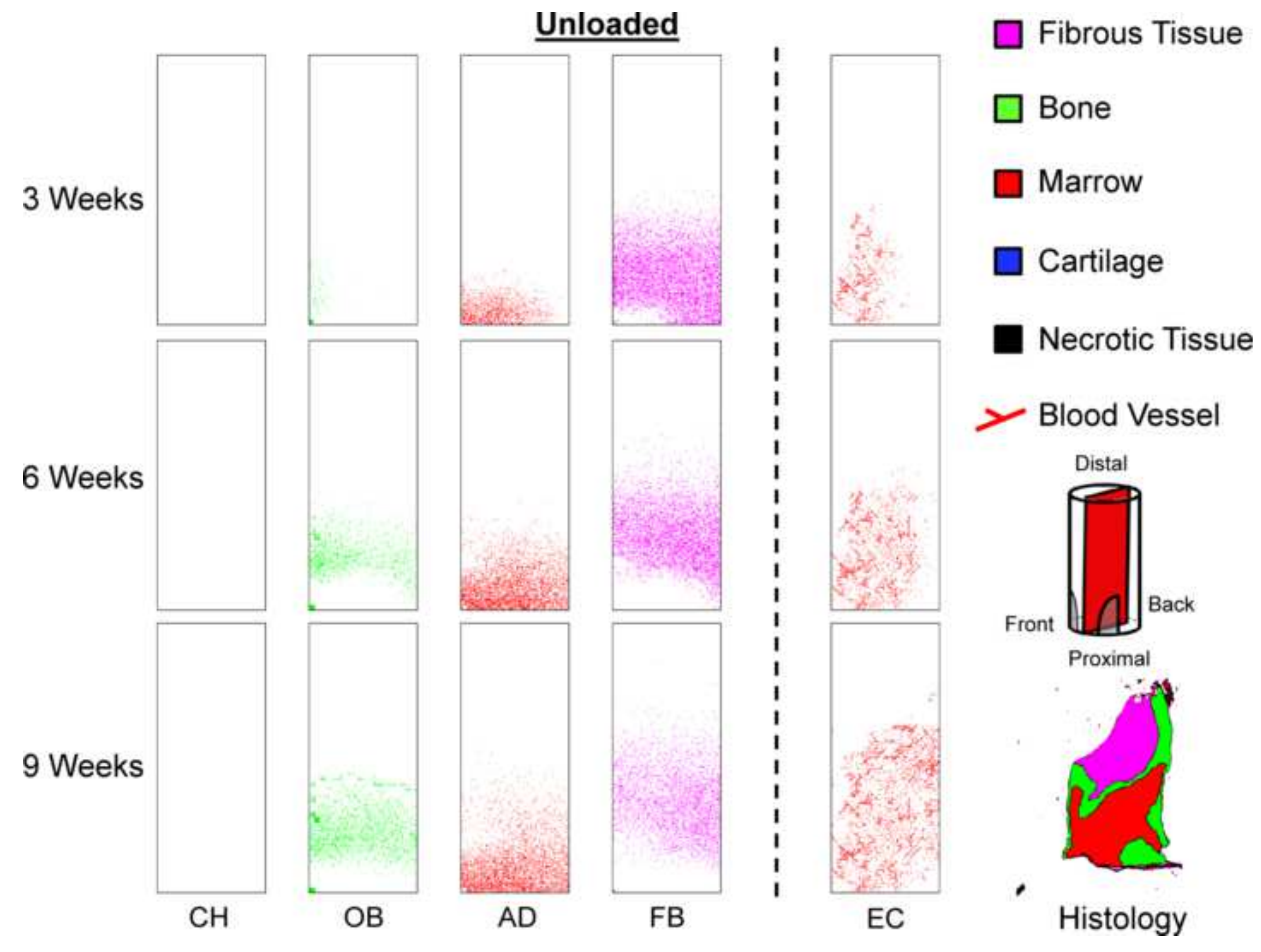 \\ re to}

Marrow

$\square$ Cartilage

Necrotic Tissue 


\section{Unloaded}

3 Weeks

6 Weeks

9 Weeks

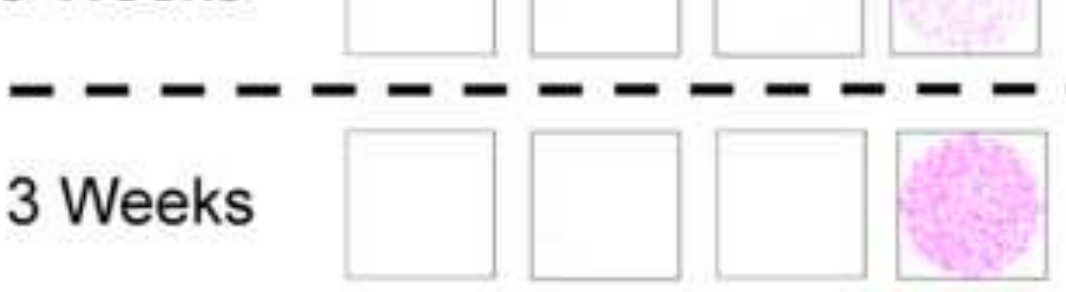

6 Weeks

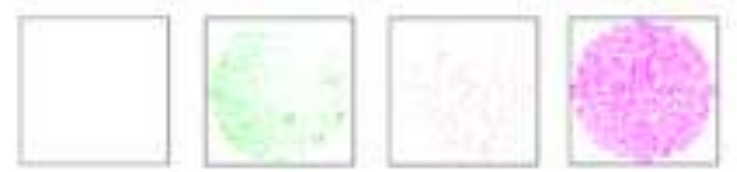

9 Weeks

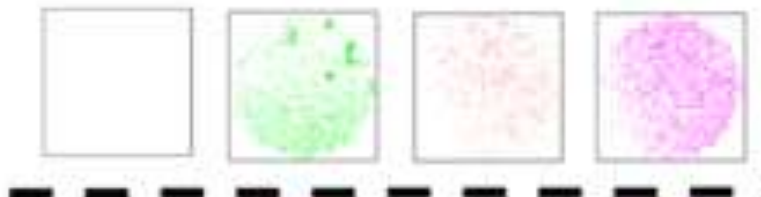

- - - - - -

3 Weeks

6 Weeks
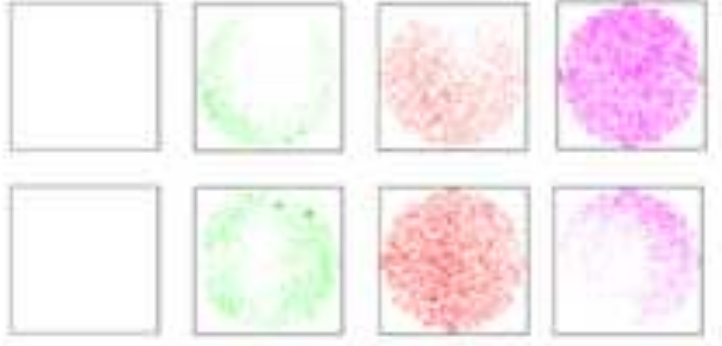

9 Weeks
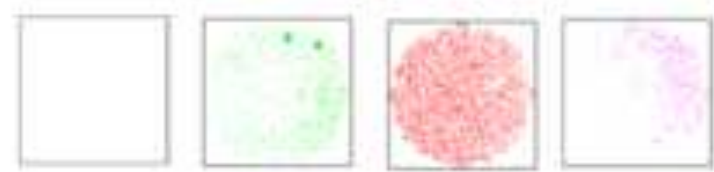

$\mathrm{CH}$

$\mathrm{OB}$

AD

FB
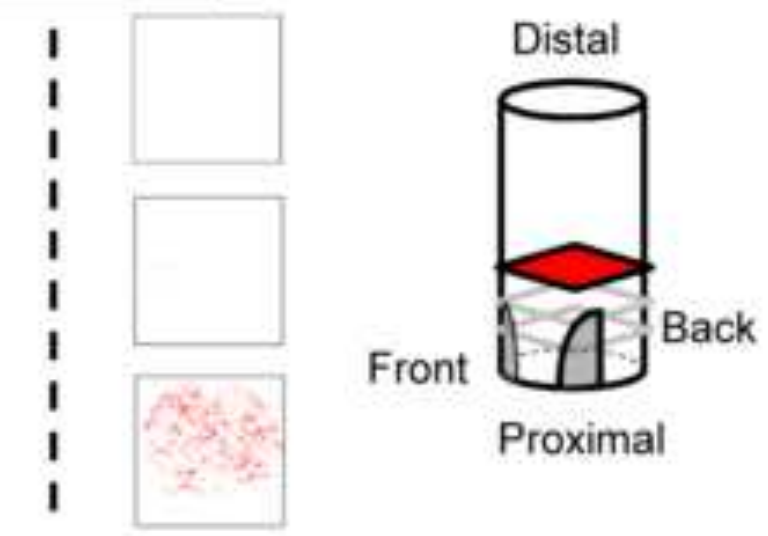

$\square$ Fibrous Tissue
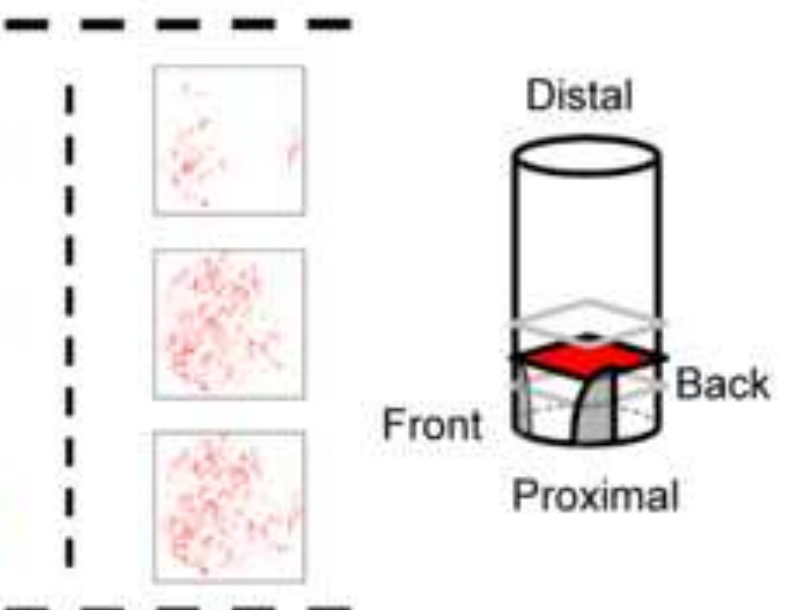

$\square$ Bone

$\square$ Marrow

$\square$ Cartilage

Necrotic Tissue
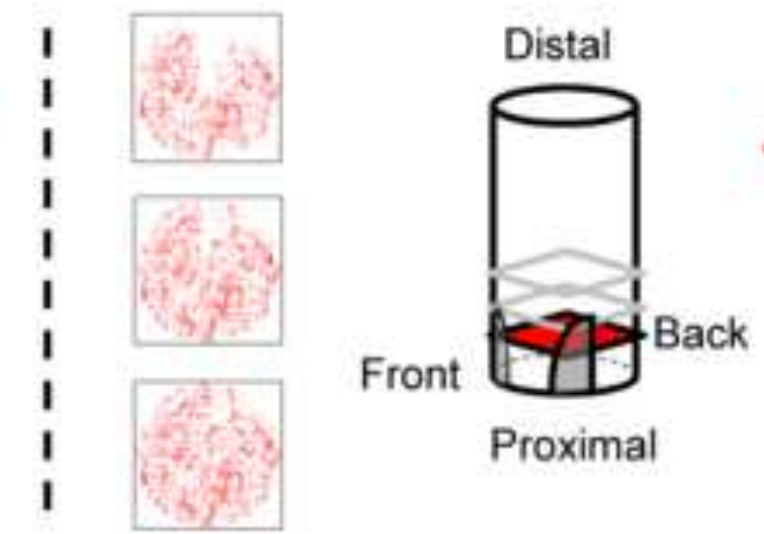

EC 


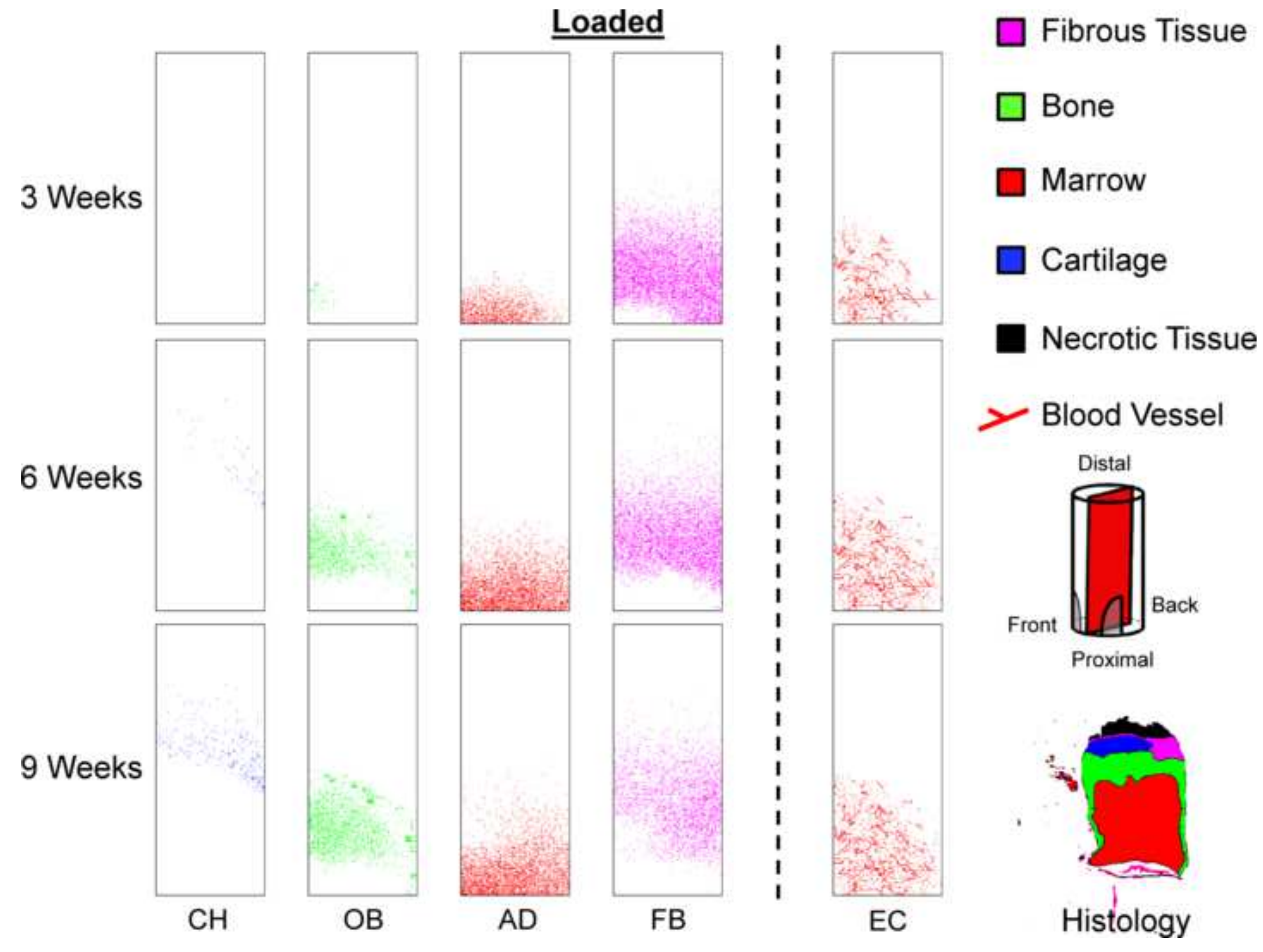

\section{Loaded}

$\square$ Fibrous Tissue

$\square$ Bone

Marrow

Cartilage

Necrotic Tissue

Blood Vessel 


\section{Loaded}

3 Weeks
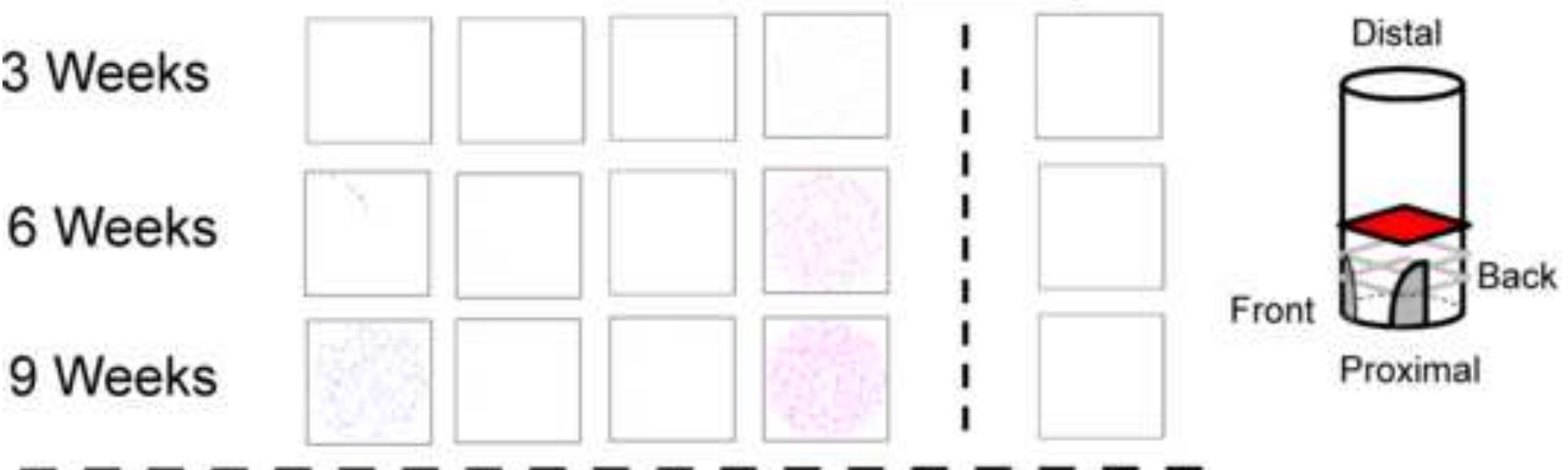

9 Weeks

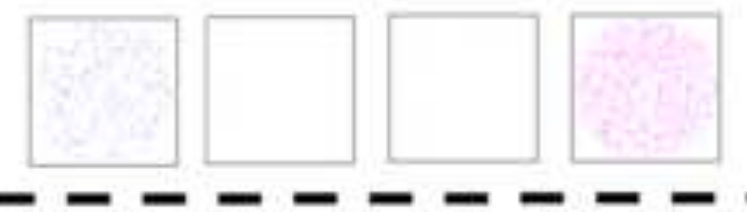

\section{Weeks}
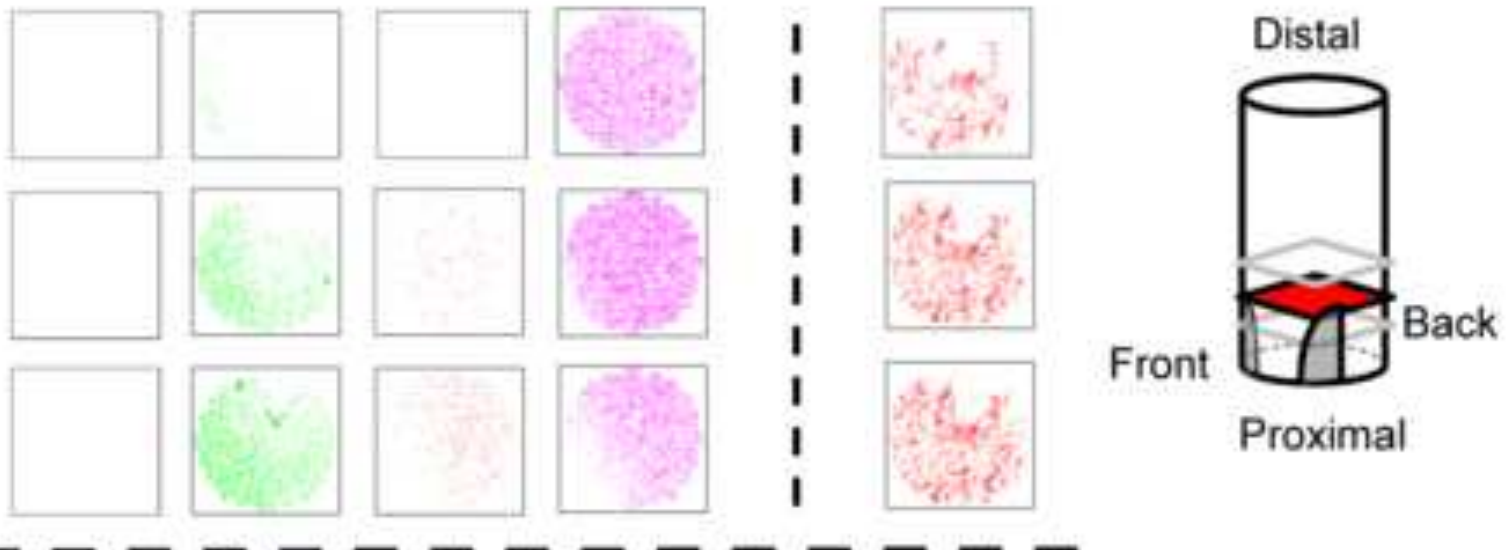

9 Weeks
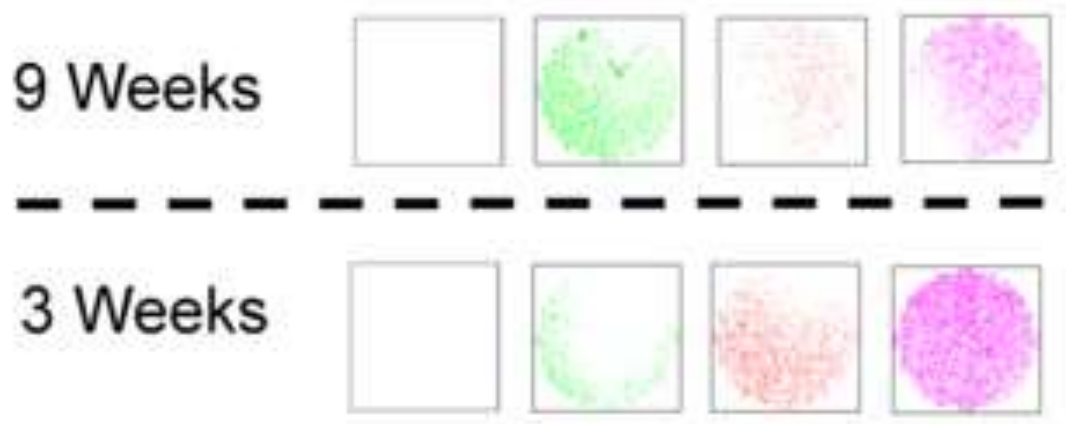

6 Weeks

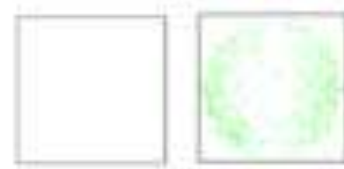

9 Weeks
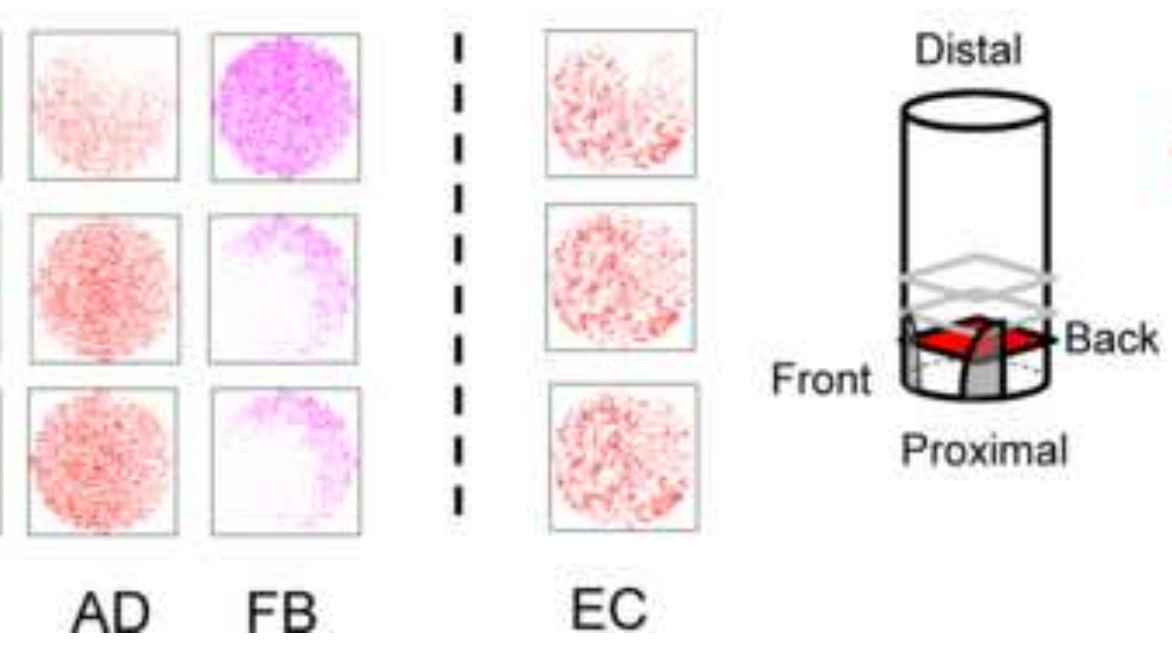

Necrotic Tissue

$\square$ Bone

$\square$ Marrow

$\square$ Cartilage

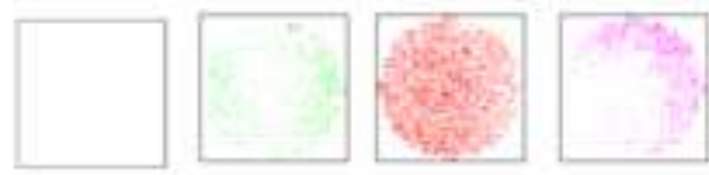

$\mathrm{CH} \quad \mathrm{OB} \quad \mathrm{AD} \quad \mathrm{FB}$

EC 


\section{Unloaded Case}

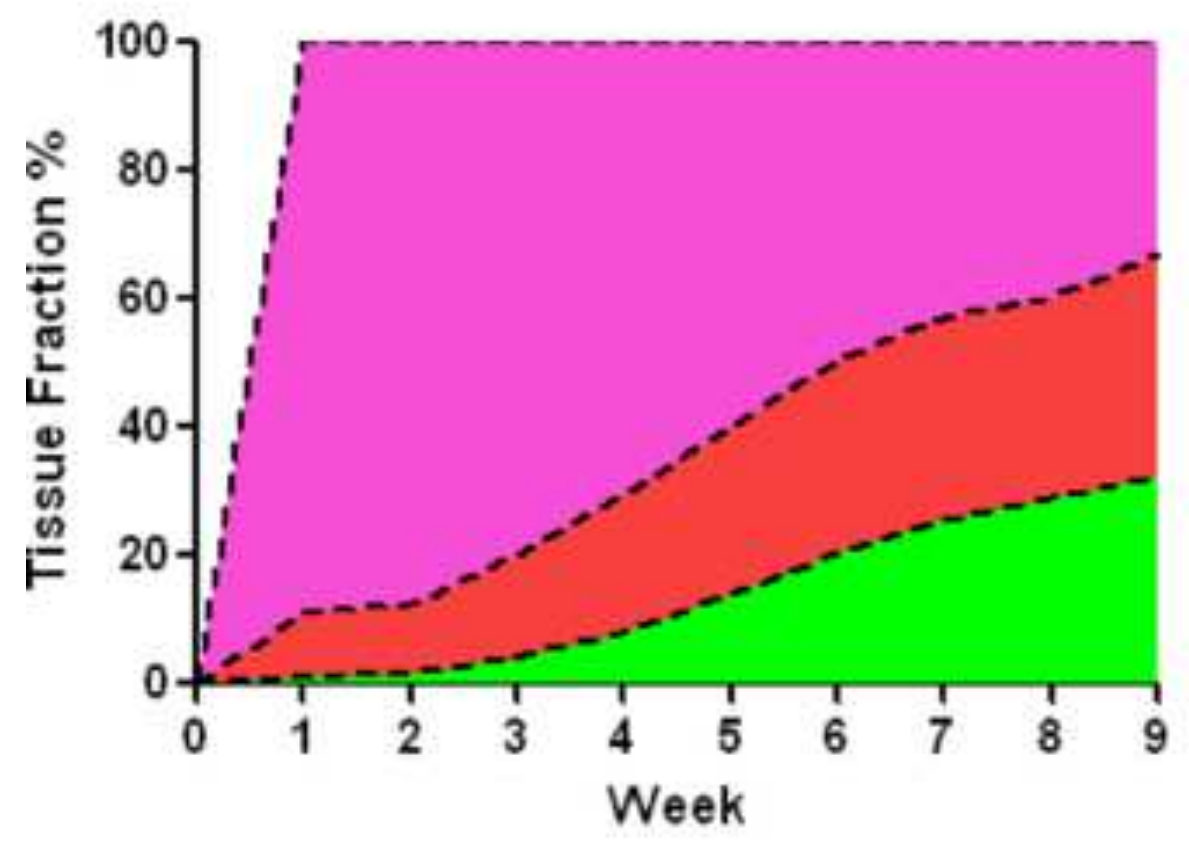

$\square$ Fibrous Tissue

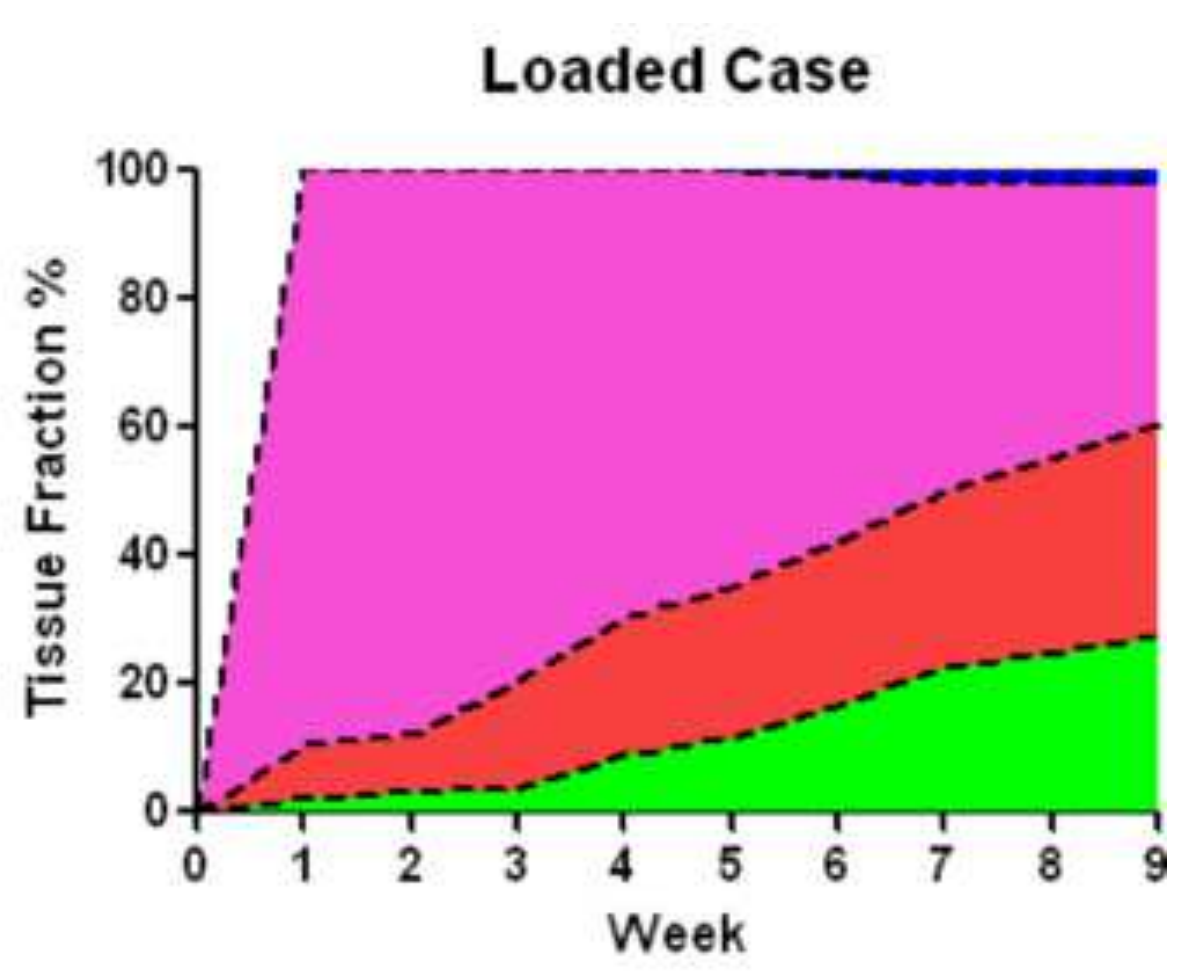

$\square$ Bone $\square$ Marrow 